\title{
PENERAPAN MODEL PEMBELAJARAN VISUALIZATION AUDITORY KINESTETIC (VAK) DALAM MENINGKATKAN HASIL BELAJAR IPS SISWA SMPN MONCOK
}

\author{
Muhammad Naharuddin Arsyad \\ IKIP Budi Utomo Malang \\ muhammadnaharuddinarsyad@budiutomomalang.ac.id \\ Helensiana Nuryati \\ Pendidikan Sejarah Dan Sosiologi, FPISH, IKIP Budi Utomo Malang \\ HelensianaNuryati@gmail.com
}

\begin{abstract}
Abstrak
Pembelajaran IPS di SMP Negeri Moncok masih terdapat berbagai permasalahan yang menyebabkan kualitas pembelajaran dan hasil belajar belum optimal. Salah satu model pembelajaran yang dapat digunakan adalah model pembelajaran Visualization Auditory Kinestetic (VAK). Penelitian ini bertujuan untuk mengetahui perbedaan hasil belajar sebelum dan sesudah penerapan model Visualization Auditory Kinesthetic.

Metode penelitian yang digunakan adalah metode eksperimen, dengan desain penelitian one group pre-test post-test design. Populasi penelitian ini adalah seluruh siswa kelas VII SMP Negeri Moncok Pengambilan sampel dilakukan melalui teknik purposive sampling yaitu satu kelas. Teknik pengumpulan data yang digunakan adalah teknik tes dan teknik dokumentasi. Teknik analisis data yang digunakan adalah teknik analisis statistik t-Test.

Berdasarkan hasil penelitian yang telah dilakukan, menggunakan rumus uji t-Test diketahui bahwa $t_{\text {hitung }}=-8,172$ dan untuk $t$ tabel diperoleh dengan cara nilai @ = $5 \%(0,05)$ dengan derajat kebebasan (df) $n-1$ atau 29-1 $=28$. Pengujian 2 sisi (signifikansi $=0,025$ ) hasil diperoleh untuk $t$ tabel adalah 2,048. Didapatkannya hasil $-\mathrm{t}$ hitung $<-\mathrm{t}$ tabel $(-8,172<-2,048)$ maka $\mathrm{HO}$ ditolak dan $\mathrm{Ha}$ diterima. Sehingga dapat disimpulkan bahwa penerapan model pembelajaran Visualization Auditory Kinestetic pada materi interaksi sosial dapat meningkatkan hasil belajar IPS Sosiologi siswa kelas VII SMP Negeri Moncok.
\end{abstract}

Kata Kunci : Model Pembelajaran, Visualization Auditory Kinesthetic, Hasil Belajar

\section{PENDAHULUAN}

Pendidikan mempunyai peranan yang sangat penting untuk menciptakan kehidupan yang cerdas, damai, terbuka, dan demokratis. Peningkatan mutu pendidikan diharapkan mampu meningkatkan kualitas (harkat dan martabat) manusia sehingga mampu beradaptasi dengan perkembangan zaman. Pendidikan merupakan suatu proses untuk membantu manusia dalam mengembangkan potensi yang ada pada dirinya sehingga mampu menghadapi segala perubahan yang 
terjadi di sekitarnya. Pendidikan di sekolah menengah pertama dimaksudkan sebagai upaya pembekalan kemampuan menengah siswa berupa kecerdasan, pengetahuan, kepribadian, akhlak mulia, serta keterampilan dan sikap yang bermanfaat bagi dirinya sesuai dengan tingkat perkembanganya, serta mempersiapkan mereka untuk melanjutkan kejenjang berikutnya. Hal tersebut dapat tercapai dengan adanya kurikulum sebagi pedoman dalam proses pembelajaran.

Kurikulum yang dilaksanakan harus seragam agar tidak terjadi perbedaan tujuan, isi, dan bahan pembelajaran antara satu wilayah dengan wilayah yang lain. Undangundang Nomor 20 Tahun 2003 tentang Sistem Pendidikan Nasional, kurikulum adalah seperangkat rencana dan pengaturan mengenai tujuan, isi, dan bahan pelajaran serta cara yang digunakan sebagai pedoman penyelenggaraan kegiatan pembelajaran untuk mencapai tujuan pendidikan tertentu.

Kurikulum yang berlaku saat ini adalah Kurikulum Tingkat Satuan Pendidikan (KTSP) dan Kurikulum 2013. Penelitian ini dilaksanakan pada sekolah yang menerapkan Kurikulum 2013 yaitu di SMP Negeri Moncok karena pelaksanaan proses pendidikan dilakukan dalam bentuk mata pelajaran pada kelas tinggi dan tematik untuk kelas rendah.

Kurikulum 2013 merupakan kurikulum yang berbasis karakter dan kompetensi (Mulyasa, 2013: 163). Kurikulum 2013 terdiri dari tujuan pendidikan, struktur dan muatan kurikulum 2013, kalender pendidikan, serta silabus. Pembelajaran Kurikulum 2013 di Sekolah Menengah Pertama menerapkan pendekatan mata pelajaran terpadu. Komponen mata pelajaran pada struktur kurikulum SMP/MTs adalah: 1) Pendidikan Agama, 2) Pendidikan Kewarganegaraan (PKn), 3) Bahasa Indonesia, 4) Bahasa Inggris, 5) Matematika, 6) IImu Pengetahuan Alam (IPA Terpadu), 7) Ilmu Pengetahuan Sosial (IPS Terpadu), 8) Seni Budaya, 9) Pendidikan Jasmani, Olahraga dan Kesehatan, dan 9) Mata pelajaran lain seperti muatan lokal dan pengembangan diri sesuai kebijakan sekolah masing-masing.

IImu pengetahuan sosial merupakan salah satu mata pelajaran yang dapat meningkatkan kemampuan berpikir secara logis, kritis, dan memberikan kontribusi dalam penyelesaian masalah sehari-hari. Mata pelajaran IPS menurut Permendiknas Nomor 22 Tahun 2006 tentang Standar Isi untuk Satuan Pendidiakn Menengah menjelaskan bahwa: Mata pelajaran IPS perlu diberikan kepada semua peserta didik (siswa) mulai dari sekolah dasar untuk membekali peserta didik (siswa) dengan kemampuan berfikir logis, analitis, sistematis, kritis, dan kreatif serta peserta didik (siswa) dapat memiliki kemampuan memperoleh, mengelola, dan memanfaatkan informasi untuk bertahan hidup 
pada keadaan yang selalu berubah, tidak pasti, dan kompetitif.

Pembelajaran IPS diharapkan mampu menciptakan siswa yang berkulitas sehingga mampu bersaing di masa yang akan datang, sedangkan dalam pelaksanaannya pembelajaran IPS di SMP Negeri Moncok masih terdapat berbagi permasalahan yang menyebabkan kualitas pembelajaran dan hasil belajar belum optimal. Siswa pada umumnya belajar melalui visual (apa yang dapat dilihat atau diamati), auditory (apa yang dapat didengar) dan kinesthetic (apa yang dapat digerakkan atau dilakukan) sehingga mereka memerlukan suatu model atau metode tertentu yang dapat memenuhi gaya belajarnya. Salah satu model pembelajaran yang dapat digunakan adalah model pembelajaran visual auditory kinesthetic (VAK).

Menurut DePorter (2014: 123) model pembelajaran VAK memfokuskan pembelajaran pada pemberian pengalaman belajar secara langsung (direct experience) dan menyenangkan. Pengalaman belajar secara langsung seperti: belajar dengan melihat (visual), belajar dengan mendengar (auditory), dan belajar dengan gerak dan praktik (kinesthetic). Pembelajaran berlangsung efektif dan efesien jika memperhatikan ketiga gaya belajar siswa. Hal ini sesuai dengan pendapat Russel (2011: 40) menjelaskan model pembelajaran VAK yaitu suatu model pembelajaran dengan memanfaatkan potensi/gaya belajar yang dimiliki siswa dengan cara melatih dan mengembangkannya secara optimal gaya belajar siswa agar hasil belajar meningkat. Hasil penelitian yang telah dilakukan, bahwa model pembelajaran visual auditory kinesthetic berpengaruh terhadap hasil belajar dan meningkatkan hasil belajar siswa.

Berdasarkan uraian di atas, peneliti tertarik untuk meneliti tentang "Penerapan Model Pembelajaran Visualization Auditory Kinestetic (VAK) dalam Meningkatkan Hasil Belajar IPS Sosiologi Materi Interaksi Sosial pada Siswa Kelas VII SMP Negeri Moncok". Dimana tujuan dari penelitian ini adalah untuk mengetahui perbedaan hasil belajar sebelum dan sesudah penerapan model Visualization Auditory Kinesthetic.

\section{TINJAUAN PUSTAKA}

1. Model pembelajaran visual auditory kinesthetic (VAK)

Model pembelajaran merupakan suatu acuan atau prosedur yang akan digunakan dalam mencapai tujuan pembelajaran. Menurut Majid (2013: 13) model pembelajaran adalah kerangka konseptual yang melukiskan prosedur yang sistematis dalam mengorganisasikan pengalaman belajar untuk mencapai tujuan belajar tertentu, dan berfungsi sebagai pedoman bagi para perancang pembelajaran dan para pengajar dalam merencanakan aktivitas belajar mengajar. 
Model pembelajaran visual auditory kinesthetic (VAK) merupakan model pembelajaran yang mengoptimalkan tiga gaya belajar yang berupa visual, auditory, dan kinesthetic untuk menjadikan siswa merasa nyaman. VAK merupakan tiga modalitas yang dimiliki oleh setiap manusia. Ketiga modalitas tersebut kemudian dikenal sebagai gaya belajar. Gaya belajar merupakan kombinasi dari bagaimana seseorang dapat menyerap dan kemudian mengatur serta mengolah informasi (Shoimin, 2014: 226).

Russel (2011: 40) menjelaskan model pembelajaran VAK yaitu suatu model pembelajaran dengan memanfaatkan potensi/gaya belajar yang dimiliki siswa dengan cara melatih dan mengembangkan secara optimal gaya belajar siswa agar hasil belajar meningkat. Adapun potensi yang dimiliki siswa dan harus dikembangkan sebagai berikut:

a. Visualization

Visual merpakan gaya belajar siswa dengan menggunakan indramata melalui mengamati, gambar, alat peraga, dan mediapembelajaran.

b. Auditori

Auditori merupakan gaya belajar siswa melalui cara mendengar,menyimak, berbicara, presentasi, mengemukakan pendapat,gagasan, menanggapai, dan berargumentasi.

c. Kinestetik

Kinestetik merupakan gaya belajar siswa melalui aktivitas fisik dan keterlibatan langsung siswa dalam proses pembelajaran.

Berdasarkan uraian di atas, peneliti menyimpulkan bahwa model pembelajaran Visual, Auditory, Kinesthetic (VAK) adalah model pembelajaran yang mengoptimalkan pada tiga gaya belajar yaitu visual, auditory, dan kinesthetic. Guru dapat mengkombinasikan ketiga gaya belajar ini pada saat peroses pembelajaran berlangsung di kelas sehingga aktivitas belajar akan lebih optimal dan menciptakan suasana belajar yang efektif, variatif, dan menyenangkan.

Model pembelajaran tentu memiliki kelebihan dan kelemahannya masing-masing, begitu pula dengan model pembelajaran VAK. Berikut kelebihan dan kelemahan model pembealajaran VAK. Shoimin (2014: 227-228) menjelaskan bahwa model pembelajaran VAK memiliki kelebihan dan kelemahan, yaitu:

a. Kelebihan model pembelajaran VAK

1) Pembelajaran akan lebih efektif karena mengombinasikan ketiga gaya belajar. 
2) Mampu melatih dan mengembangkan potensi siswa yang telah dimiliki oleh pribadi masing-masing.

3) Memberikan pengalaman langsung kepada siswa.

4) Mampu melibatkan siswa secara maksimal dalam menemukan dan memahami suatu konsep melalui kegiatan fisik, seperti demonstrasi, percobaan, observasi, dan diskusi aktif.

5) Mampu menjangkau setiap gaya pembelajaran siswa.

6) Siswa yang memiliki kemampuan bagus tidak akan terhambat oleh siswa yang lemah dalam belajar karena model ini mampu melayani kebutuhan siswa yang memiliki kemampuan di atas rata-rata.

b. Kelemahan model pembelajaran VAK Kelemahan dari model pembelajaran VAK yaitu tidak banyak orang mampu mengkombinasikan ketiga gaya belajar tersebut. Sehingga, orang yang hanya mampu menggunakan satu gaya belajar, hanya akan mampu menangkap materi jika menggunakan gaya belajar yang lebih memfokuskan kepada salah satu gaya belajar yang didominasi.
2. Belajar dan Hasil Belajar

Menurut Gagne belajar adalah perubahan disposisi atau kemampuan yang dicapai seseorang melalui aktivitas. Perubahan disposisi tersebut bukan diperoleh langsung dari proses pertumbuhan seseorang secara alamiah (Suprijono 2012: 2). Sadiman mengungkapkan belajar adalah suatu proses kompleks yang terjadi pada semua orang dan berlangsung seumur hidup, sejak dia masih bayi hingga ke liang lahat. (Musfiqon, 2012: 3)

Salah satu pertanda bahwa seseorang telah belajar adalah adanya perubahan tingkah laku dalam dirinya. Susanto (2014: 4) menjelaskan bahwa belajar adalah suatu aktivitas mental yang berlangsung dalam interaksi aktif antara seseorang dengan lingkungan, dan menghasilkan perubahan-perubahan dalam pengetahuan, pemahaman, keterampilan, dan nilai sikap yang bersifat relative konstan dan berbekas.

Tujuan utama yang ingin dicapai dalam kegiatan pembelajaran adalah hasil belajar. Hasil belajar digunakan untuk mengetahui sebatas mana siswa dapat memahami serta mengerti materi pembelajaran yang telah diberikan dan melakukan evaluasi proses pembelajaran yang telah berlangsung sehingga dapat memberikan tindak lanjut dari hasil belajar. 


\begin{abstract}
Menurut Nawawi hasil belajar dapat diartikan sebagai tingkat keberhasilan siswa dalam mempelajari materi pelajaran disekolah yang dinyatakan dalam skor yang diperoleh dari hasil tes mengenal sejumlah materi pelajaran tertentu. Hasil belajar adalah perubahanperubahan yang terjadi pada diri siswa, baik menyangkut aspek kognitif, afektif, dan psikomotor dari kegiatan belajar. Kawasan kognitif berkenaan dengan ingatan atau pengetahuan dan kemampuan intelektual serta keterampilankeetermpilan. Kawasan afektif mengembangkan sikap-sikap, minat dan nilai serta pengembangan pengertian atau pengetahuan dan penyesuaian diri yang memadai. Kawasan psikomotor adalah kemampuan-kemampuan menggiatkan dan mengkoordinasikan gerak (Susanto 2013: 5).
\end{abstract}

\section{Definisi Mata Pelajaran IPS Di SMP/MTs}

Mata pelajaran IImu Pengetahuan Sosial (IPS) di SMP dan MTs merupakan salah satu mata pelajaran yang wajib ditempuh oleh siswa SMP dan MTs sebagaimana yang diungkapkan oleh Sapriya (2009: 12) bahwa IPS pada kurikulum sekolah (satuan pendidikan), pada hakikatnya merupakan mata pelajaran wajib sebagaimana dinyatakan dalam Undang-Undang Nomor 20 Tahun 2003 tentang Sistem Pendidikan Nasional pada pasal 37 yang berbunyi bahwa kurikulum pendidikan dasar dan menengah wajib memuat ilmu pengetahuan sosial.

Mata pelajaran IImu Pengetahuan Sosial (IPS), sebagai mata pelajaran yang wajib ditempuh oleh peserta didik, merupakan mata pelajaran yang disusun secara sistematis, komprehensif, dan terpadu sebagaimana yang tertuang dalam Permendiknas Nomor 22 Tahun 2006. Pembelajaran IPS yang disusun secara terpadu, memiliki tujuan agar peserta didik dapat memperoleh pemahaman yang lebih luas dan mendalam pada bidang ilmu yang berkaitan. Oleh sebab itu, pembelajaran IPS di tingkat SMP dan MTs di Indonesia seharusnya menerapkan pembelajaran IPS secara terpadu.

Muhammad Numan Somantri (2001: 44) menjelaskan dan merumuskan tentang IPS di tingkat sekolah adalah "suatu penyederhanaan disiplin ilmu-ilmu sosial, psikologi, filsafat, ideologi negara, dan agama yang diorganisasikan dan disajikan secara ilmiah dan psikologis untuk tujuan pendidikan". Dengan demikian, maka mata pelajaran IPS dilndonesia ialah penyederhanaan ilmuilmu sosial yang disajikan secara ilmiah dan psikologis yang memiliki tujuan untuk bidang pendidikan. 


\section{Metode Penelitian}

Metode penelitian yang di gunakan dalam penelitian ini adalah metode penelitian eksperimen. Sugiyono (2016: 107) menyatakan, bahwa metode penelitian eksperimen dapat diartikan sebagai metode penelitian yang digunakan untuk mencari pengaruh perlakuan tertentu terhadap yang lain dalam kondisi terkendalikan. Jenis penelitian ini adalah Pre-Experimental Design (non designs). Adapun desain penelitian yang digunakan adalah one group pre-test post-test design. Dalam desain ini, sebelum diberikan perlakuan terhadap sampel terlebih dahulu diberi pre-test (tes awal) untuk mengetahui kemampuan awal siswa.

Setelah diberikan tes awal (pretest) sampel tersebut diberikan perlakuan (treatment) dengan menggunakan model visualization auditory kinesthetic dan diakhir pembelajaran atau sesudah perlakuan sampel diberi post-test (tes akhir) untuk mengetahui sejauh mana penerapan model pembelajaran visualization auditory kinesthetic dalam meningkatkan hasil belajar IPS Sosiologi Materi Interaksi Sosial yang telah dilaksanakan. Berikut ini adalah desain penelitiannya:

\section{$\mathrm{O}_{1} \mathrm{X}^{\mathrm{O}} 2$}

\section{Gambar 1. Desain penelitian}

(Sugiyono, 2016: 111)
01 = nilai pre-test (sebelum diberi perlakuan)

$\mathrm{O} 2$ = nilai post-test (setelah diberi perlakuan)

$\mathrm{X}=$ treatment (perlakuan) model pembelajaran Visualization Auditory Kinestethic.

Populasi dalam penelitian ini adalah seluruh siswa kelas VII SMP Negeri Moncok dan sampel yang digunakan adalah purposive sampling sebanyak 29 siswa kelas kelas VII B. Teknik pengumpulan data yang digunakan berupa tes dan dokumentasi yang kemudian dianalisis secara kuantitatif. Untuk menganalisis data hasil eksperimen menggunakan rumus t-test :

$$
t=\frac{M d}{\sqrt{\frac{\Sigma(x d)^{2}}{N(N-1)}}}
$$

Keterangan :

$$
\begin{aligned}
\mathrm{t}= & \text { uji- } \mathrm{T} \\
\mathrm{Md}= & \text { Mean dari perbedaan pretest } \\
& \text { dan post-test }(\mathrm{x} 2-\mathrm{x} 1) \\
\mathrm{Xd}= & \text { deviasi masing-masing subjek }(\mathrm{d} \\
& -\mathrm{Md}) \\
\Sigma \times 2 \mathrm{~d}= & \text { jumlah kuadrat deviasi } \\
\mathrm{N}= & \text { subjek pada sampel } \\
\mathrm{d} \cdot \mathrm{b}= & \text { ditentukan dengan } \mathrm{N}-1 \\
& \text { (Arikunto, 2013:307). }
\end{aligned}
$$

Dalam analisis ini, peneliti menggunakan Penghitungan manual dengan microsoft office excel. Apabila $\mathrm{t}$ hitung $>\mathrm{t}$ tabel maka $\mathrm{HO}$ ditolak Keterangan : 
dan Ha diterima, tetapi sebaliknya apabila $t$ hitung $<\mathrm{t}$ tabel maka $\mathrm{HO}$ diterima dan Ha ditolak.

\section{Hasil dan Pembahasan}

Pre-test dilaksanakan sebelum peneliti menerapkan model pembelajaran Visualization Auditory Kinesthetik pada pembelajaran IPS Sosiologi materi interaksi sosial. Tujuan dilakukakan pre-test untuk mengetahui kemampuan awal siswa mengenai hasil belajar IPS Sosiologi materi interaksi sosial. Adapun hasil pre-test dapat di lihat pada tabel berikut ini:

Tabel 1. Nilai Hasil Pre-test siswa

\begin{tabular}{lr}
\hline Mean & 53,79310345 \\
\hline Standard Error & 2,598492984 \\
\hline Median & 50 \\
\hline Mode & 50 \\
\hline Standard Deviation & 13,99331297 \\
\hline Sample variance & 195,8128079 \\
\hline Minimum & 30 \\
\hline Maximum & 80 \\
\hline
\end{tabular}

Dari tabel tersebut dapat dilihat bahwa nilai rata-rata pre-test yang diperoleh siswa yaitu 53,79 dengan simpangan baku 13,993. Nilai terendah yang diperoleh siswa yaitu 30 sedangkan nilai tertinggi adalah 80. Adapun nilai tengah 50 dan nilai yang sering muncul 50 .

Post-Test dilakukan sesudah peneliti memberikan treatment dengan menerapkan model pembelajaran Visualization Auditory Kinesthetic pada pembelajaran IPS Sosiologi materi Interaksi Sosial. Post-test bertujuan untuk mengetahui kemampuan akhir hasil belajar siswa pada mata pelajaran IPS Sosiologi materi Interaksi Sosial. Adapun hasil post-test dapat dilihat pada tabel berikut:

Tabel 2. Nilai Hasil Post-Test siswa

\begin{tabular}{lr}
\hline Mean & 77,5862069 \\
\hline Standard Error & 1,76551339 \\
\hline Median & 80 \\
\hline Mode & 80 \\
\hline Standard Deviation & 9,50758059 \\
\hline Sample variance & 90,3940887 \\
\hline Minimum & 60 \\
\hline Maximum & 90 \\
\hline
\end{tabular}

Dari tabel tersebut dapat dilihat bahwa nilai rata-rata post-test 77,58 dengan simpangan baku 9,507. Nilai terendah yang diperoleh siswa yaitu 60 dan nilai tertinggi adalah 90. Adapun nilai tengah yaitu 80 dan nilai yang sering muncul 80 . Selanjutnya adalah hasil perbandingan data sebelum penerapan model pembelajaran VAK (pre-test) dengan data hasil setelah penerapan model pembelajaran VAK (post-test) yang disajikan dalam bentuk tabel berikut ini:

Tabel 3. Perbandingan nilai Pre-test dan Post-test

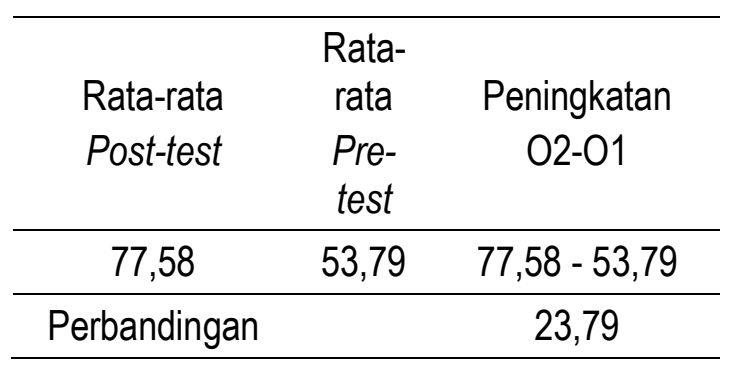


Berdasarkan data pada tabel 3 tersebut, dapat di ketahui terjadi peningkatan rata-rata hasil pre-test dan post-test yaitu sebesar 23,79. Hasil tersebut membuktikan bahwa secara matematis model pembelajaran visualization auditory kinesthetic dapat meningkatkan hasil belajar dan untuk pengujian hipotesis dalam penelitian ini dilakukan dengan menggunakan rumus t-Test. t-Test digunakan untuk mengetahui perbedaan hasil belajar sebelum dan sesudah penerapan model pembelajaran Visualization Auditory Kinesthetic dalam meningkatkan hasil belajar IPS Sosiologi materi interaksi sosial pada siswa kelas VII SMP Negeri Moncok. Berikut ini adalah hipotesis yang dipakai

$\mathrm{Ha}$ : Terdapat perbedaan yang signifikan pada hasil belajar mahasiswa sebelum dan sesudah menggunakan model pembelajaran Visualization

\section{Auditory Kinesthetic}

$\mathrm{HO}$ : Tidak terdapat perbedaan yang signifikan pada hasil belajar mahasiswa sebelum dan sesudah menggunakan model pembelajaran Visualization

\section{Auditory Kinesthetic}

Pengujian ini menggunakan penghitungan manual dengan Microsoft office excel. Kriteria pengujian $\mathrm{Ha}$ diterima jika $\mathrm{t}_{\text {hitung }}$ $>t$ tabel dan Ha ditolak jika $t$ nitung $<t$ tabel. Untuk lebih jelas dapat dilihat pada tabel berikut:
Tabel 4. Hasil Uji t-Test

\begin{tabular}{lrr}
\hline & Pre-test & Post-test \\
\hline Mean & 53,7931 & 77,5862 \\
\hline Observations & 29 & 29 \\
\hline df & 28 & \\
\hline t Stat & $-8,1723$ & \\
\hline $\begin{array}{l}\text { T Critical two- } \\
\text { tail }\end{array}$ & 2,0484 & \\
\hline
\end{tabular}

Berdasarkan hasil penghitungan uji tTest secara manual dengan Microsoft office excel maka diperoleh nilai $t$ hitung $=-8,172$ dan untuk $t$ tabel diperoleh dengan cara nilai @ = 5 $\% / 2=2,5 \%$ (untuk uji 2 sisi) dengan derajat kebebasan (df) n-1 atau 29-1 = 28. Pengujian 2 sisi ( signifikansi $=0,025$ ) hasil diperoleh untuk $t$ tabel adalah 2,048. Dari hasil yang diperoleh maka -t hitung < - t tabel $(-8,172<-2,048)$ maka dapat dinyatakan bahwa $\mathrm{HO}$ ditolak dan $\mathrm{Ha}$ diterima.

Hal ini membuktikan bahwa terdapat perbedaan sebelum dan sesudah penerapan model pembelajaran Visualization Auditory Kinesthetic dalam meningkatkan hasil belajar IPS Sosiologi materi interaksi sosial pada siswa kelas VII SMP Negeri Moncok. Hasil penelitian ini sesuai dengan teori Russel (2011: 40) yang menyatakan model pembelajaran VAK yaitu suatu model pembelajaran dengan memanfaatkan potensi/gaya belajar yang dimiliki siswa dengan cara melatih dan mengembangkannya secara optimal gaya belajar siswa agar hasil belajar meningkat. 


\section{PENUTUP}

\section{Kesimpulan}

Terdapat perbedaan sebelum dan sesudah penerapan model pembelajaran Visualization Auditory Kinesthetic dalam meningkatkan hasil belajar IPS Sosiologi materi interaksi social pada siswa kelas VII SMP Negeri Moncok. Hal ini dapat dilihat dengan adanya peningkatan nilai rata-rata pre-test sebelum diberikan treatment dan nilai rata-rata post-test setelah diberikan treatment dengan penerapan model pembelajaran Visualization Auditory Kinesthetic (VAK). Rata-rata nilai pretest yaitu sebesar 53,79 mengalami peningkatan pada nilai post-test 77,58 . Peningkatan nilai pre-test dan post-test sebesar 23,79. Berdasarkan uji t-Test diperoleh nilai $-t$ hitung $-8,172<-t$ tabel $-2,048$ dengan taraf signifikan 0,05 , sehingga $\mathrm{HO}$ ditolak dan $\mathrm{Ha}$ diterima.

\section{Saran}

1. Bagi Guru

Guru hendaknya menerapkan model pembelajaran yang kreatif salah satunya adalah penerapan model pembelajaran Visualization Auditory Kinesthetic sehingga pembelajaran berjalan lebih efektif dan hasil belajar yang dicapai siswa lebih maksimal..

2. Bagi Sekolah

Diharapkan bagi pihak sekolah dapat menambah fasilitas sarana dan prasarana sekolah yang lebih menunjang untuk menciptakan pembelajaran yang lebih berkualitas dan bermakna.

3. Bagi Peneliti Lain

Hasil penelitian ini dapat dijadikan referensi khususnya dengan menggunakan model pembelajaran Visual Auditory Kinesthetic (VAK), serta dapat dijadikan perbandingan dan landasan pengembangan penelitian lebih lanjut dalam pengembangan model pembelajaran Visual Auditory Kinesthetic (VAK).

\section{DAFTAR PUSTAKA}

Arikunto, Suharsimi. 2013. Prosedur Penelitian Suatu Pendekatan Praktik. Jakarta: PT Rineka Cipta.

DePorter, Bobi dkk. 2014. Quantum Teaching. Bandung: Kaifa.

Majid, Abdul. 2013. Strategi Pembelajaran. Bandung: Rosdakarya.

Mulyasa. 2013. Pengembangan dan Implementasi Kurikulum 2013. Bandung: PT Remaja Rosdakarya.

Musfiqon. 2012. Pengembangan Media dan Sumber Pembelajaran. Jakarta: PT Prestasi Pustakaraya.

Russel, Lou. 2011. The Accelerated Learning Fieldbook. Bandung: Nusa Media.

Shoimin, Aris. 2014. 68 Model Pembelajaran Inovatif dalam Kurikulum 2013. Yogyakarta: Ar-Ruzz Media.

Somantri, Numan. 2001. Menggagas Pembaharuan Pendidikan IPS. Bandung: PT Remaja Rosdakarya. 
Suprijono, Agus. 2012. Cooperative Learning. Yogyakarta: Pustaka Belajar.

Susanto, Ahmad. 2014. Teori Belajar dan Pembelajaran. Jakarta: Kencana Prenada Media Group.

Susanto, Ahmad. 2015. Teori Belajar dan Pembelajaran. Jakarta: Kencana Prenada Media Group.

Sugiyono. 2016. Metode Penelitian Pendidikan Pendekatan Kuantitatif, Kualitatif, dan $R \& D$. Bandung: Alfabeta.
Tim Penyusun. 2003. Undang-Undang Sistem Pendidikan Nasional. Jakarta: Sekertariat Negara.

Tim Penyusun. 2006. Permendiknas No. 22 Tahun 2006 Tentang Standar Isi untuk satuan pendidikan dasar dan menengah. Jakarta: Depdiknas. 